\title{
TU/e EmonOWEN

\section{Design and control of a magnetically suspended ceiling actuator with infinite planar stroke}

\section{Citation for published version (APA):}

Overboom, T. T., Smeets, J. P. C., Jansen, J. W., \& Lomonova, E. A. (2013). Design and control of a magnetically suspended ceiling actuator with infinite planar stroke. Applied Mechanics and Materials, 416-417, 492-502. https://doi.org/10.4028/www.scientific.net/AMM.416-417.492

DOI:

10.4028/www.scientific.net/AMM.416-417.492

Document status and date:

Published: 01/01/2013

\section{Document Version:}

Accepted manuscript including changes made at the peer-review stage

\section{Please check the document version of this publication:}

- A submitted manuscript is the version of the article upon submission and before peer-review. There can be important differences between the submitted version and the official published version of record. People interested in the research are advised to contact the author for the final version of the publication, or visit the $\mathrm{DOI}$ to the publisher's website.

- The final author version and the galley proof are versions of the publication after peer review.

- The final published version features the final layout of the paper including the volume, issue and page numbers.

Link to publication

\section{General rights}

Copyright and moral rights for the publications made accessible in the public portal are retained by the authors and/or other copyright owners and it is a condition of accessing publications that users recognise and abide by the legal requirements associated with these rights.

- Users may download and print one copy of any publication from the public portal for the purpose of private study or research.

- You may not further distribute the material or use it for any profit-making activity or commercial gain

- You may freely distribute the URL identifying the publication in the public portal.

If the publication is distributed under the terms of Article 25fa of the Dutch Copyright Act, indicated by the "Taverne" license above, please follow below link for the End User Agreement:

www.tue.nl/taverne

Take down policy

If you believe that this document breaches copyright please contact us at:

openaccess@tue.nl

providing details and we will investigate your claim. 


\title{
Design and control of a magnetically suspended ceiling actuator with infinite planar stroke
}

\author{
T.T. Overboom ${ }^{1, a}$, J.P.C. Smeets $1^{1, b}$, J.W. Jansen ${ }^{1, c}$ and E. Lomonova ${ }^{1, d}$ \\ ${ }^{1}$ Eindhoven University of Technology, Dep. of Electrical Engineering \\ Den Dolech 2, 5612 AZ Eindhoven, The Netherlands \\ at.t.overboom@tue.nl, b.j.p.c.smeets@tue.nl, cj.w.jansen@tue.nl and de.lomonova@tue.nl
} Keywords: Linear synchronous motors, magnetic levitation, permanent-magnet motors and planar
actuators.

\begin{abstract}
This paper presents the design and control of a magnetically suspended ceiling actuator which combines four iron-cored linear actuators and a checkerboard permanent magnet array for an infinite planar stroke. When the actuators are rotated with respect to the PM array, it is shown that the thrust and normal force produced by the three-phase linear actuators can be controlled by applying Park's transformation. The design of the iron-cored linear actuators is optimized for minimum losses when the translator inside the ceiling actuator and a payload are accelerated in the $x y$-plane. The optimization is performed using an analytical model is. Simulations of the optimized design with a $3 \mathrm{D}$ FE-model, show a maximum tracking error of $1 \mu \mathrm{m}$ and rotations of $30 \mu \mathrm{rad}$ when the translator is moved and controlled in 6 DOF.
\end{abstract}

\section{Introduction}

Magnetically suspending a planar actuator underneath a stationary frame (ceiling), provides an alternative for $x y$-positioning systems that are operated in clean rooms. In [1] and [2], a structure for this so-called ceiling actuator is presented. It consists of four linear actuators which provide single-sided magnetic suspension and planar propulsion of a moving translator. In both papers, the linear actuators are arranged such that two of them generate a thrust force along $x$ and the other two generate a force along $y$. Additionally, all actuators are also able to actively control the normal $(z-)$ force. By separately exciting the four linear actuators it is possible to control the active magnetic bearing in six degrees-of-freedom (DOF).

In [1] several actuator topologies are compared and it is concluded that a three-phase excited permanent-magnet (PM) actuator with a slotted iron yoke achieves the highest acceleration. By the inclusion of PMs and iron, a passive normal force acts between the translator and the ceiling. This force is used to passively counteract the gravitational force acting on the translator and provide fail-safe operation of the ceiling actuator. The topology comparison in [1] is made for a moving magnet configuration; the linear actuators are fixed to the ceiling and PM arrays for each actuator are attached to the moving translator. In [2] the performance of four slotted linear actuators are analyzed when used in a moving coil configuration; the actuators are moved while the PM arrays are fixed. In [1] and [2], the planar stroke of the translator is limited because the PM arrays only have an alternating magnetization pattern along one direction. To move the translator over large distances in the $x y$-plane, a checkerboard PM array has to be employed. Such PM arrays are used in long-stroke magnetically levitated planar actuators [3][4]. In these ironless actuators, the translator is moved above a stationary frame. In [3][4], the planar actuators have long-shaped coils which are rotated $45^{\circ}$ with respect to the PM array. Consequently, the individual coils only produce a thrust force along $x$ or $y$.

In this paper, the translator configuration presented in [2] is combined with such a checkerboard PM array, as shown in Fig. 1. The three-phase linear actuators with a slotted iron yoke are fixed to a carrier and also rotated with respect to the PM array. The magnets are glued to a nonconducting and nonferromagnetic back-plate. An analytical model is derived to show the working principles of a single linear actuator and optimize its design when it is used in the ceiling actuator. The model and 
working principles are verified with 3D finite element simulation. Finally, the influence of the force and torque ripples on the position error is analyzed when the optimized design for the ceiling actuator is controlled in 6 DOF.

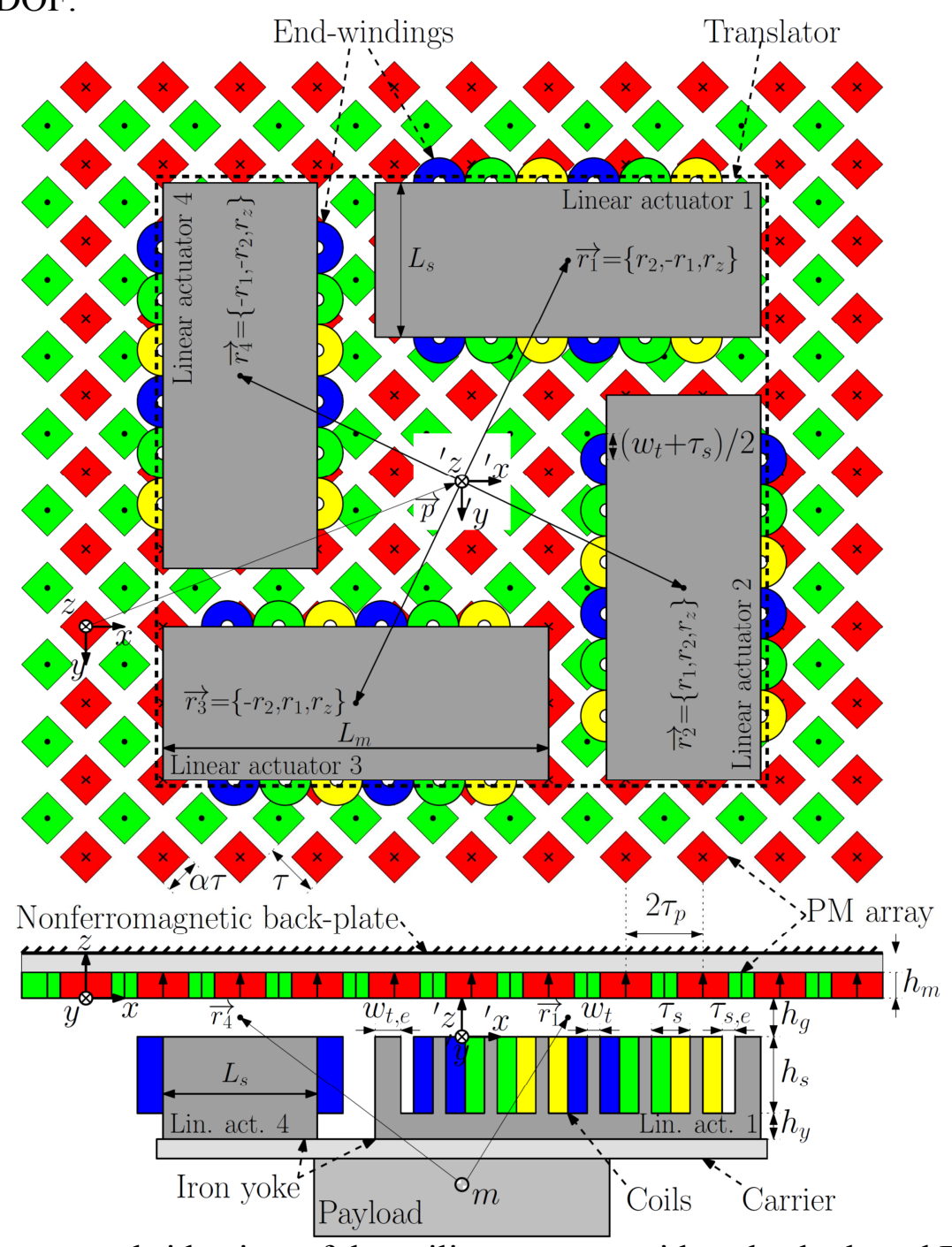

Fig. 1. Bottom and side view of the ceiling actuator with a checkerboard PM array.

\section{Analytical model of a single actuator}

For the design of the ceiling actuator as shown in Fig. 1, an analytical model of a single linear actuator and the checkerboard PM array is required. In the remainder of this section, linear actuator 1 is considered. The leading dimensions are indicated in Fig. 1.

Coordinate system

Two coordinate systems are used. A local coordinate system $\left(\left\{x^{\prime} y,{ }^{\prime} z\right\}\right)$ is fixed to the center of the translator, as shown in Fig. 1. Its location is given by the vector $\vec{p}=\left\{p_{x}, p_{y}, p_{z}\right\}$ in the global coordinate system $(\{x, y, z\})$. Both coordinate systems are rotated $45^{\circ}$ with respect to the rectangular shape of the magnets. During operation $p_{z}=h_{g}$, where $h_{g}$ is the nominal airgap length. The position and orientation of the translator are given by $\vec{x}=\left[p_{x} p_{y} p_{z} \psi \theta \phi\right]^{T}$, where $\psi, \theta$, and $\phi$ are the rotations about the $x$-, $y$-, and $z$-axis, respectively. In the analytical model it is assumed that $\psi=\theta=\phi=0$ rad.

3D magnetic field model

Because of the alternating magnetization vector in the xy-plane, the magnetic fields produced by the PM array have to be described in three dimensions. The fields are obtained by modeling the iron yoke as an infinitely permeable and infinitely large plate. End-effects due to finite length of the yoke are, therefore, neglected. The current carrying coils inside the slotted structure of the iron yoke are 
replaced by infinitely small current sheet on the boundary of the iron yoke at ' $z=0 \mathrm{~m}$. The reduced reluctance of the slotted structure is accounted for by scaling the airgap length with Carter's coefficient [5], which is obtained from as

$$
k_{C}=\frac{w_{t}+\tau_{s}}{w_{t}+\tau_{s}-\gamma g_{t}}
$$

where $g_{t}=p_{z}+h_{m}$ and $\gamma$ is given by

$$
\gamma=\frac{4}{\pi}\left\{\frac{\tau_{s}}{2 g_{t}} \tan ^{-1}\left(\frac{\tau_{s}}{2 g_{t}}\right)-\log \sqrt{1+\left(\frac{\tau_{s}}{2 g_{t}}\right)^{2}}\right\} .
$$

As a result, the effective airgap length in the analytical model is calculated according to

$$
h_{g, e f f}\left(p_{z}\right)=k_{C} p_{z} \text {. }
$$

The method of imaging is only applied to the iron yoke because the PM array has no back-iron. Although the total magnetic field is the sum of the field produced by the original PM array and its mirror, for the force calculation it is sufficient to describe the magnetic field inside the airgap due to the original PM array alone. Its flux density distribution is described with double Fourier series which contains two harmonic numbers, $\{i, j\}$. A more detailed description of this model is given in [3]. For readability, only the flux density distribution of the first harmonic (described in the local coordinate system) is given

$$
\begin{aligned}
& B_{x_{x,\{1,1\}}}=B_{p,\{1,1\}}\left({ }^{\prime} z, p_{z}\right) \sin \left(\frac{\pi}{\tau_{p}}\left(' x-p_{x}\right)\right) \\
& B_{y_{y,\{1,1\}}}=B_{p,\{1,1\}}\left(' z, p_{z}\right) \sin \left(\frac{\pi}{\tau_{p}}\left({ }^{\prime} y-p_{y}\right)\right) \\
& B_{z,\{1,1\}}=B_{p,\{1,1\}}\left(' z, p_{z}\right)\left(\cos \left(\frac{\pi}{\tau_{p}}\left(' y-p_{y}\right)\right)-\cos \left(\frac{\pi}{\tau_{p}}\left({ }^{\prime} x-p_{x}\right)\right)\right)
\end{aligned}
$$

where $\tau_{p}=\tau / \sqrt{2}$ is the magnetic pole pitch, and

$$
B_{p,\{1,1\}}\left(' z, p_{z}\right)=\frac{16}{\pi^{2}} B_{r} e^{\frac{\pi}{\tau_{p}}\left(' z-h_{g, e f f}\left(p_{z}\right)\right)} \frac{\left(e^{h_{m} \pi / \tau_{p}}-1\right) \sin ^{2}(\pi \alpha / 2)}{\mu_{r}-1+e^{h_{m} \pi / \tau_{p}}\left(\mu_{r}+1\right)}
$$

In (5), $B_{r}$ and $\mu_{r}$ are the remanence and the relative permeability of the permanent magnets, respectively, and $\alpha=\tau_{m} / \tau$ is the magnet to pole pitch ratio.

Force and torque calculation

For the force calculation, it is assumed that to the yoke length, $L_{m}$, and yoke width, $L_{s}$, are equal to $2 \tau_{p} n_{l}$ and $2 \tau_{p} n_{s}$, respectively. $n_{l}$ and $n_{s}$ are integers.

The electromagnetic force produced by the slotted linear actuator is obtained as the Lorentz force acting on the current sheet and its mirror as a result of the magnetic flux density due to the original PM array. It is only calculated on the straight part of the coils inside the slots. The end-windings are ignored in the force calculation. The coils are fed with three-phase currents which are commutated in synchronism with the displacement $p_{x}$. By applying Park's transformation [6] and considering only the first harmonic of the magnetic field, only an electromagnetic thrust force along $x$ is obtained

$$
F_{x}=k I_{q}=\frac{24}{\pi} \tau_{p}^{3} n_{c p} n_{s}\left(\frac{1}{2}+\cos \left(\frac{\pi w_{t}}{2 \tau_{p}}\right)\right) B_{p,\{1,1\}}\left(0, p_{z}\right) N_{t} I_{q}
$$

where $n_{c p}$ is the number of coils per phase, $k$ is the motor constant, $N_{t}$ is the number of turns per coil, $w_{t}$ is the tooth width and $I_{q}$ is the $q$-axis currents. Due to the absence of any ferromagnetic material behind the PM array and a low $\mu_{r}$ of the magnet material, the same expression for the electromagnetic normal force is obtained. This force component, however, is controlled with the $d$-axis current, $I_{d}$. 
The passive normal force between the PM array and the iron yoke is obtained as the reluctance force acting between the original PM array and its mirror. This force is calculated by applying the Maxwell stress tensor at the position of the iron boundary $\left({ }^{\prime} z=0 \mathrm{~m}\right)$ and evaluating it over the surface of the yoke

$$
F_{z, r}=\frac{8}{\mu_{0}} n_{l} n_{s} \tau_{p}^{2} \sum_{i=1}^{I} \sum_{j=1}^{J}\left(B_{p,\{i, j\}}\left(0, p_{z}\right)\right)^{2}
$$

where $B_{p,\{i, j\}}\left(' z, p_{z}\right)$ is the peak value of the flux density for each harmonic in the double Fourier series. As a result, the total normal force becomes

$$
F_{z}=F_{z, r}+k I_{d} \text {. }
$$

According to (6) and (8), the linear actuator in combination with the checkerboard magnet array can be operated in the same way as the linear actuators presented in [1] and [2] (only a varying magnetization vector along the length of the actuator); i.e. the thrust force is linearly controlled with the $q$-axis current while the normal force linearly depends on the $d$-axis current.

Due to the simplifications made in this model, it is difficult to correctly calculate the torque produced by the linear actuator. For the optimization it is, therefore, presumed that the forces are produced in the middle of the airgap and in the middle of the $x y$-plane above the iron yoke. Consequently, the torque acting on the mass center point of the translator is calculated by multiplying the forces with the arms indicated in Fig. 1.

Flux density inside the iron yoke

The electromagnetic forces are only linear with the current when the iron yoke is not saturated. Therefore, a magnetic equivalent circuit (MEC) for the linear actuator is used to limit the flux density inside the various parts of the yoke during the optimization. As will be shown in Section IV, the magnetic field produced by the PM array is very low in the optimized designs of the ceiling actuator. As such, the MEC only calculates the flux density inside the yoke due to the three-phase currents. Moreover, it primarily accounts for the slot leakage because no iron is place behind the PM array. In the MEC 6 parallel reluctances are used inside the slot.

\section{Force and torque decoupling}

Because the ceiling actuator is a single-sided active magnetic bearing, all forces and torques acting on the translator have to be controlled with the three-phase currents inside the linear actuators. Using (6) and (8), the total sum of forces and torques produced by all linear actuators can be rewritten as

$$
\vec{w}_{\text {des }}=\Gamma(\vec{x}) \vec{i}+\vec{w}_{r}(\vec{x})
$$

where $\vec{w}_{\text {des }}=\left[F_{x}^{*} F_{y}^{*} F_{z}^{*} T_{x}^{*} T_{y}^{*} T_{z}^{*}\right]^{T}$ is the desired wrench vector obtained from a position controller and $\vec{i}=\left[I_{d, 1} I_{q, 1} I_{d, 2} I_{q, 2} I_{d, 3} I_{q, 3} I_{d, 4} I_{q, 4}\right]^{T}$ is the current vector with $I_{d, i}$ and $I_{q, i}$ being the $d$-and $q$-axis currents for each linear actuator, respectively. $\Gamma(\vec{x})$ is a matrix describing the linear relationship between $\vec{i}$ and $\vec{w}_{\text {des }} \cdot \vec{w}_{r}$ is a wrench vector containing the total reluctance force and torque components acting on the translator.

To achieve the desired wrench vector, $\vec{i}$ has to be solved from (9), giving

$$
\vec{i}(\vec{x})=\Gamma^{-}(\vec{x})\left(\vec{w}_{\text {des }}-\vec{w}_{r}(\vec{x})\right)
$$

where the $\Gamma^{-}(\vec{x})$ is an inverse matrix of $\Gamma(\vec{x})$. Because the ceiling actuator is over-actuated, no unique solution exists for $\Gamma^{-}(\vec{x})$. Therefore, the Moore-Penrose inverse is used since it minimizes the dissipated ohmic losses inside the coils [3]

$$
\Gamma^{-}(\vec{x})=\Gamma^{T}(\vec{x})\left(\Gamma(\vec{x}) \Gamma^{T}(\vec{x})\right)^{-1} .
$$




\section{Design optimization}

This section presents the optimization process of the ceiling actuator shown in Fig. 1. The general structure of the linear actuators is optimized using the analytical model presented in Section II. The end-teeth are designed separately.

Optimization objective

The objective of the optimization process is to minimize the mean ohmic losses dissipated inside the coils when the translator is accelerated in the $x y$-plane. Iron losses inside the yoke are neglected. The ohmic losses are obtained by solving the currents with (10) and considering only one turn inside each coil $\left(N_{t}=1\right)$. For $\vec{w}_{\text {des }}=[\operatorname{am} \operatorname{amgm} 000]^{T}$, where $a$ is the desired acceleration, the mean ohmic losses dissipated in all four linear actuators are obtained as

$$
P_{\text {mean }}=\frac{\rho_{c u} V_{c}}{8 p_{f} k^{2} h_{s}^{2} \tau_{s}^{2}}\left(\left(m g-4 F_{z, r}\right)^{2}+4 \delta m^{2} a^{2}+4 \delta m^{2} a^{2} \frac{r_{z}^{2}}{r_{1}^{2}+r_{2}^{2}}\right)
$$

where $m$ is the translator mass, $p_{f}=0.7$ is the packing factor of the coils, $\rho_{c u}=1.678 \cdot 10^{-8} \Omega \mathrm{m}$ is the electrical resistivity of the copper, and $V_{c}$ is the total volume of the coils including the end-windings. $\delta$ is the duty cycle which is defined as the amount of time the translator is accelerated over the total amount of time the ceiling actuator is operated.

In (12) the first part inside the brackets can be recognized as the ohmic losses required to suspend the translator, while the second part is the ohmic losses due to the acceleration. The third part is the dissipated losses as a result of torque compensation when the translator is accelerated. It shows that a center point of mass close to the airgap ( $\operatorname{small} r_{z}$ ) and a large footprint of the translator (large $r_{1}$ and $r_{2}$ ) is desired for low dissipation. The term in front of the brackets can be recognized as the inverse of the steepness, which is given in $\left(\mathrm{N}^{2} / \mathrm{W}\right)$. The design of the ironless planar actuators $\left(F_{z, r}=0 \mathrm{~N}\right)$ as presented in [3] and [4], is optimized by minimizing the ratio of the mass squared over the steepness. However, this is not possible with the ceiling actuator due to the presence of the reluctance force, $F_{z, r}$. Moreover, the steepness (which includes the motor constant $k$ ) and $F_{z, r}$ are strongly related. Consequently, unlike the ironless planar actuator, the design of the ceiling actuator depends on the desired acceleration in the $x y$-plane.

After the first optimization step, the end-teeth of the iron yoke are designed for minimum force ripples using a 2D harmonic model which includes the slotting and finite length of the iron yoke [7]. This model only considers an alternating magnetization vector along the length of the linear actuator and, therefore, is not able to correctly calculate the mean thrust and normal force when a checkerboard PM array is used. The ripple forces are obtained when the linear actuator is moved along $x$ and the maximum current is supplied to the $q$-axis.

Design assumptions and constraints

The structure as shown in Fig. 1 will be optimized. A combination of three coils per four magnet poles is selected for a high winding factor. Each linear actuator contains two coils per phase $\left(n_{c p}=2\right)$ and the yoke width is equal to $4 \tau_{p}\left(n_{s}=2\right)$. Although the end-teeth are not optimized in the first optimization step, they are accounted for by an increased yoke length, $n_{l}=2 n_{c p}+1$. The four linear actuators are fixed to a carrier and are placed such that the translator size is $200 \times 200 \mathrm{~mm}$. The translator mass is obtained as $m=4 m_{a}+m_{c}+m_{l}$, where $m_{c}=2 \mathrm{~kg}$ is the carrier mass and $m_{l}=4 \mathrm{~kg}$ is the payload mass. The mass of the linear actuators, $m_{a}$, is determined by the iron yoke $\left(7850 \mathrm{~kg} / \mathrm{m}^{3}\right)$ and the copper coils $\left(8900 \mathrm{~kg} / \mathrm{m}^{3}\right)$. It is assumed that the mass center point is located $10 \mathrm{~mm}$ below the yokes. The yoke will consist of laminations made of M270-35A. Therefore, the flux density inside the yoke is limited to $1.5 \mathrm{~T}$. Finally, $h_{m}>4 \mathrm{~mm}$ and $h_{y}>5 \mathrm{~mm}$ for manufacturability.

The desired acceleration is $5 \mathrm{~m} / \mathrm{s}^{2}$. However, if the design is optimized for this acceleration, the iron yoke will saturate when disturbances have to be compensated for during acceleration of the translator. Therefore, $\mathrm{a}=7 \mathrm{~m} / \mathrm{s}^{2}$ during the optimization.

Optimization results

The optimization is performed with sequential quadratic programming in MATLAB and four designs are shown in Table 1. The table also shows the optimization variables. Designs 1 and 2, 
respectively, use sintered $\mathrm{NdFeB}$ magnet material with a high remanence and plastic bonded $\mathrm{NdFeB}$ magnet material with a lower remanence. Table 1 shows that design 1 has higher losses than design 2 due to a lower motor constant. This result is in contradiction with ironless planar actuators, where a magnet grade with high $B_{r}$ is preferred. It is further noticed that the magnetic field produced by the PM array in both designs is low by selecting a relatively large airgap length and minimum magnet height. The reason for this low magnet loading is to reduce $F_{z, r}$ since it quadratically depends on the flux density. As a consequence, $k$ is also small and the dissipated losses are high during acceleration.

Table 1 Dimensions and performance of the optimized designs (fixed optimization variables are indicated in bold)

\begin{tabular}{|c|c|c|c|c|}
\hline Design \# & 1 & 2 & 3 & 4 \\
\hline Optimization variables & \multicolumn{4}{|c|}{ Value } \\
\hline$B_{r}(\mathrm{~T})$ & 1.2 & \multicolumn{3}{|c|}{0.77} \\
\hline$\mu_{r}$ & 1.03 & \multicolumn{3}{|c|}{1.2} \\
\hline$\delta$ & 1 & 1 & \multicolumn{2}{|c|}{0.25} \\
\hline$h_{g}(\mathrm{~mm})$ & 3.55 & 1.91 & 2.35 & 3 \\
\hline$\tau_{p}(\mathrm{~mm})$ & 11.6 & 11.5 & 11.5 & 12 \\
\hline$\tau_{s}(\mathrm{~mm})$ & 10.1 & 10.2 & 10.3 & 10.9 \\
\hline$h_{y}(\mathrm{~mm})$ & 5 & 5 & 5 & 5 \\
\hline$h_{s}(\mathrm{~mm})$ & 17.3 & 18.5 & 18.5 & 19.2 \\
\hline$h_{m}(\mathrm{~mm})$ & 4 & 4 & 4 & 4.2 \\
\hline$\alpha$ & 0.64 & 0.68 & 0.66 & 0.75 \\
\hline \multicolumn{5}{|l|}{\begin{tabular}{|l|} 
Parameters \\
\end{tabular}} \\
\hline$w_{t}(\mathrm{~mm})$ & 5.4 & 5.1 & 5 & 5.1 \\
\hline$m=4 m_{a}+m_{c}+m_{l}(\mathrm{~kg})$ & 10.7 & 10.8 & 10.8 & 11.4 \\
\hline $4 F_{z, r}(\mathrm{~N})$ & 191 & 192 & 136 & 142 \\
\hline$k \cdot h_{s} \cdot \tau_{s} / 2\left(\mathrm{~N} \mathrm{~mm}^{2} / \mathrm{A}\right)\left(N_{t}=1\right)$ & 3.4 & 4 & 3.43 & 3.81 \\
\hline \multicolumn{5}{|c|}{ Peak acceleration: $\vec{w}_{d e s}=[7 m 7 m g m 000]^{T}$} \\
\hline Mean losses (W) & 569 & 437 & 136 & 140 \\
\hline Suspension losses $\left(a=0 \mathrm{~m} / \mathrm{s}^{2}\right)(\mathrm{W})$ & 129 & 97 & 17 & 15 \\
\hline Peak current density $\left(\mathrm{A} / \mathrm{mm}^{2}\right)$ & 16.5 & 14 & 13.7 & 13.1 \\
\hline \multicolumn{5}{|c|}{ Nominal acceleration: $\vec{w}_{d e s}=[5 m 5 m g m 000]^{T} \& \delta=0.25$} \\
\hline Mean losses $(\mathrm{W})$ & 185 & 140 & 77.7 & 79 \\
\hline Coil temperature $\left({ }^{\circ} \mathrm{C}\right)$ & 213 & 162 & 100 & 96 \\
\hline
\end{tabular}

Designs 1 and 2 have the lowest ohmic losses when the ceiling actuator is continuously accelerated $(\delta=1)$. However, at zero acceleration a significant amount of power is dissipated to suspend the translator. In design $3, \delta=0.25$ to account for a motion profile. This design is almost identical to design 2, except for a different airgap length. In design 3, the larger airgap length results in a lower passive normal force and, hence, in less ohmic losses dissipated for suspension of the translator mass. This drop is larger than the increase of the losses associated with acceleration. The latter increase is caused by a lower motor constant.

Because of mechanical reasons, $h_{g}$ and $\tau_{p}$ are fixed in design 4 . On one hand, this design results in higher losses when compared to design 3 . On the other hand, the coil temperature has decreased because of a larger contact area with the surrounding air. This temperature is estimated when a $=5$ $\mathrm{m} / \mathrm{s}^{2}, \delta=0.25$, and only natural convection is considered $\left(h_{c o n v}=15 \mathrm{~W} / \mathrm{m}^{2} / \mathrm{K}\right)$. Choosing a larger $\tau_{p}$ would result in an even lower coil temperature but it also results in a translator size larger than 200x200 mm. As shown in the table, designs 1 and 2 have higher losses for the same acceleration and would require additional cooling to reduce the coil temperature.

Finally, a parametric sweep is performed for the design of the end-teeth in design 4 . The smallest force ripples are obtained with $w_{t, e}=6.8 \mathrm{~mm}$ and $\tau_{s, e}=3.2 \mathrm{~mm}$. This results in $L_{m}=116 \mathrm{~mm}$ instead of $L_{m}=120 \mathrm{~mm}$ as assumed in the first step of the optimization. 


\section{FE-simulation of a single linear actuator}

A single linear actuator based on design 4 in Table 1 has been modeled with 3D Finite Element (FE) analysis. This model has been implemented in Cedrat FLUX3D and used to verify the electromagnetic model and analyze the force and torque ripples. Fig. 2 shows the forces obtained from FE-simulations when this linear actuator is moved along $y$ and the maximum current is applied to the $q$-axis. It has to be noted that these results are obtained for $h_{g}=2.75 \mathrm{~mm}$. The thrust force, $F_{x}$, is $10 \%$ lower than estimated with the analytical model, while the normal force, $F_{z}$, is $4 \%$ higher. $F_{y}$ has a small offset $0.2 \mathrm{~N}$ but it has a large ripple of $0.9 \mathrm{~N}$. The same ripple is also present in $F_{z}$.

The stack width of design 4 is equal to $4 \tau_{p}=48 \mathrm{~mm}$ because the analytical model is derived for $L_{s}=2 n_{s} \tau_{p}$, where $n_{s}$ is an integer. As shown in Fig. 2, however, the force ripples in $F_{y}$ and $F_{x}$ as function of $p_{y}$ are significantly reduced when $L_{s}=\left(2 n_{s}+0.5\right) \tau_{p}=4.5 \tau_{p}=54 \mathrm{~mm}$. In case of $F_{z}$, the ripple is $1.5 \%$ of its mean value. It has been verified that the ripples as function of $p_{x}$ are in same order of magnitude. In Fig. 2 it is also shown that the mean values of $F_{x}$ and $F_{z}$ for $L_{s}=54 \mathrm{~mm}$ have increased with $12.5 \%$. In the remained of this paper, design 4 with $L_{s}=54 \mathrm{~mm}$ is analyzed. In this new design, $\mathrm{m}=12 \mathrm{~kg}$.
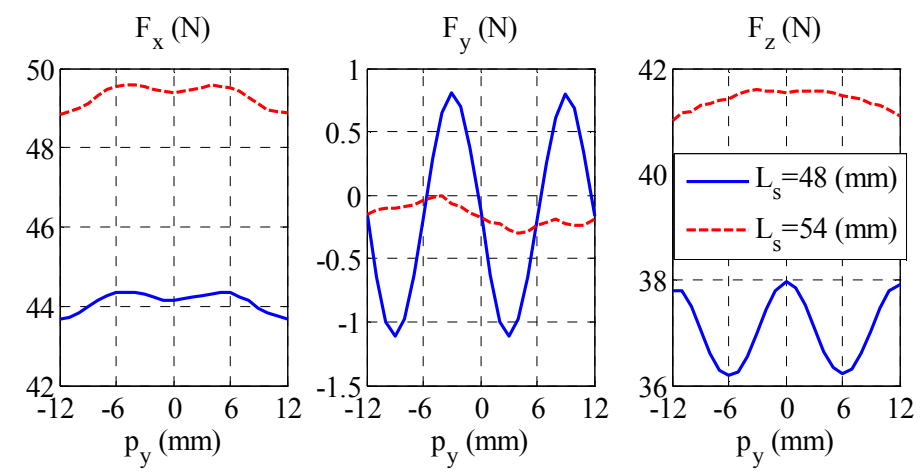

Fig. 2. Force profiles as function of py obtained for different stack width. The maximum current is supplied to the q-axis.

Fig. 3 shows the motor constant and normal force as function of the current density when linear steel $\left(\mu_{r}=5000\right)$ and nonlinear steel (M270-35A) is used in the yoke. Again, the current is supplied to the $q$-axis. Up to $14 \mathrm{~A} / \mathrm{mm}^{2}$, the motor constants for both types of steel are within $1 \%$ of each other. This is current value is $7 \%$ higher than the limit of $13.1 \mathrm{~A} / \mathrm{mm}^{2}$ calculated with the MEC presented in Section II D. Due to the relative permeability of the magnet material and the excitation of the three-phase coils, the normal force contains an additional reluctance force which is not modeled in (8). As shown in Fig. 3, at $13.1 \mathrm{~A} / \mathrm{mm}^{2}$ it increases the normal force by $4 \%$ when compared to the force at zero current.
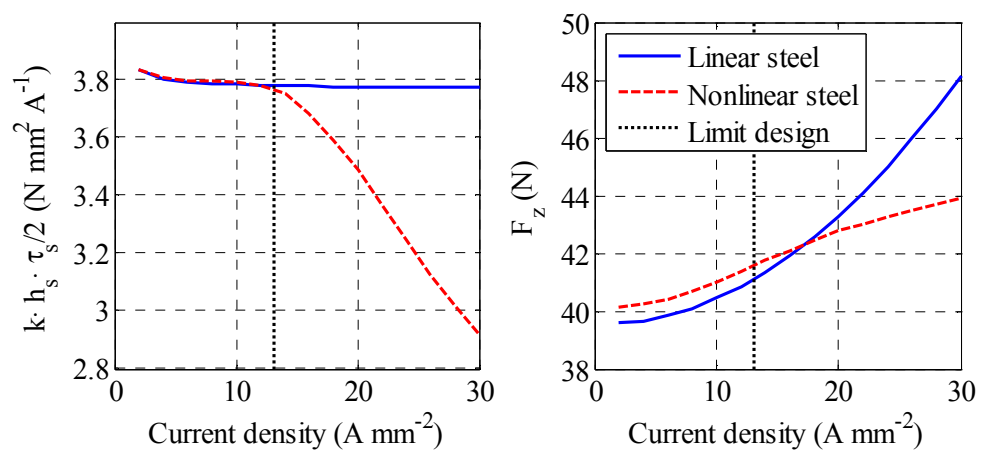

Fig. 3. Motor constant (left) and normal force (right) as function of the current density when linear and nonlinear steel is used in the yoke $\left(L_{s}=54 \mathrm{~mm}\right)$.

The force and torque profiles are also calculated when the translator is moved over two magnetic pole pitches in the $x y$-plane with a step size of $1 \mathrm{~mm}$. For a reduced calculation time, these simulations are performed by modeling the individual magnets as infinitely thin nonmeshed coils which have a total current equal to $B_{r} h_{m} / \mu_{0}\left(\mu_{r}=1\right)$. In this manner it is possible to move the PM array with respect to 
the actuator without remeshing the FE-model. Also the three-phase coils are modeled with nonmeshed coils. The torque is calculated on a point located $10 \mathrm{~mm}$ below the iron yoke and centered in the xy-plane.

The force and torque profiles when no current is supplied to the linear actuator are shown in Fig. 4. These profiles are the reluctance forces and torques acting between the iron yoke and PM array. All force ripples are smaller than $0.3 \mathrm{~N}$. The average passive normal force, $F_{z, r}$, of $39.2 \mathrm{~N}$ is slightly lower than shown in Fig. 2. All torque components are small. $T_{x}$ and $T_{y}$ show a dominant variation which depends on $p_{y}$ or $p_{x}$, respectively, and has a periodicity equal to $\tau_{p}$.
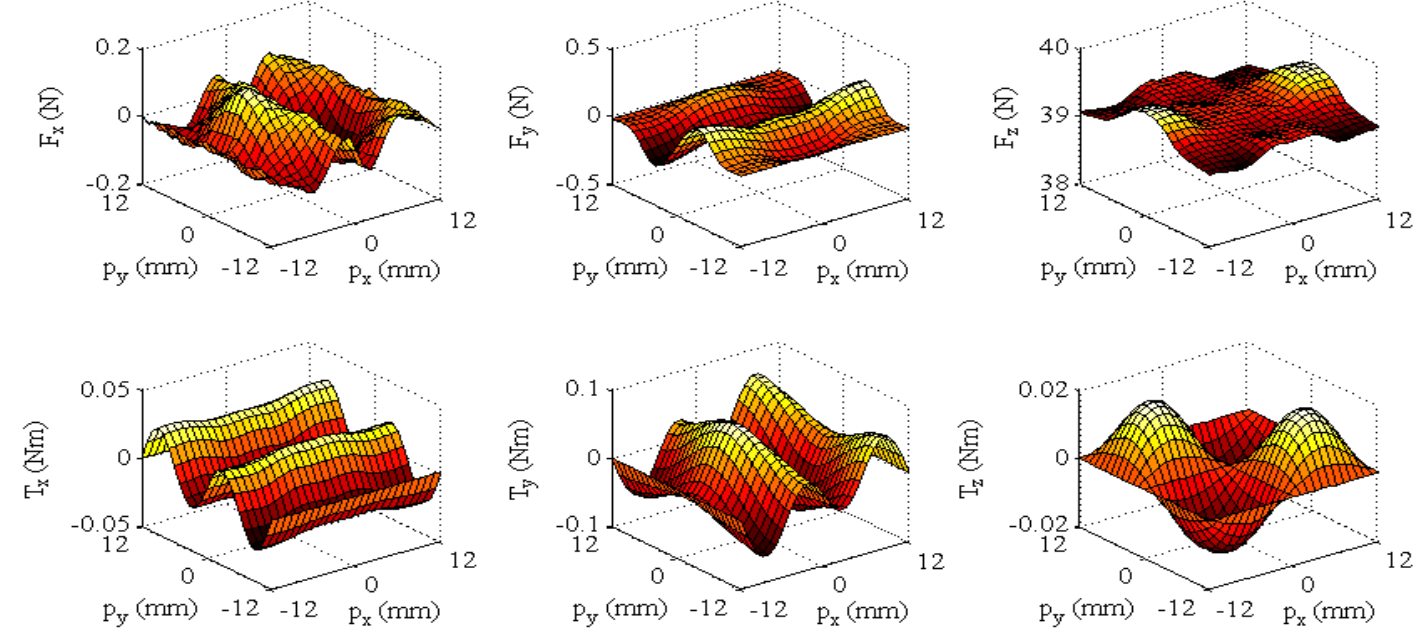

Fig. 4. Reluctance force and torque profiles of a single linear actuator.
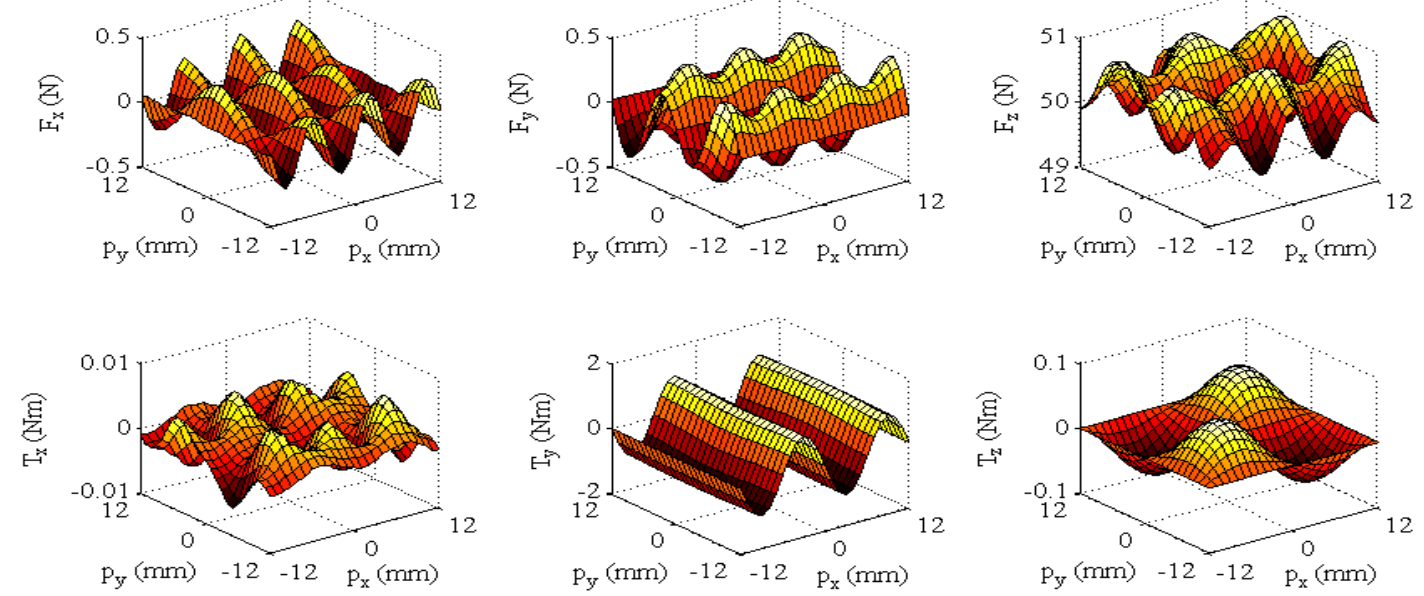

Fig. 5. Electromagnetic force and torque profiles produced by a single linear actuator when the peak current is applied to the d-axis.

The force and torque profiles are also simulated when the maximum current is injected to the coils of the linear actuator. The currents are only commuted in synchronism with the $p_{x}$. The electromagnetic forces and torques are shown in Fig. 5 and 6 for a $d$-and $q$-axis current, respectively. These profiles are obtained by performing simulations with the respective currents and subtracting the profiles of Fig. 4. As shown in Fig. 5, the $d$-axis current mainly produces an electromagnetic force along $z$ with a mean value of $50.5 \mathrm{~N}$ and a variation of approximately $2 \%$. Only a small $F_{x}$ and $F_{y}$ is produced and it is presumed that these force components are acting on the end-windings of the coils. In the figure it is also shown that the $d$-axis current produces a considerable torque about $y$, while the other two torque components are an order of magnitude lower. Similar to a linear actuator with a conventional PM array, $T_{y}$ dominantly varies as function of $p_{x}$ and has a periodicity equal to $\tau_{p}$. The same variation of $T_{y}$ plus an offset is observed in Fig. 6 . The offset is the result of the thrust force, $F_{x}$, produced by the $q$-axis current. In this case, $F_{x}$ has a mean value of $48.2 \mathrm{~N}$ and a variation of $2 \%$. Again, all other electromagnetic force and torque components are small as function of the $q$-axis current. These results show that $F_{x}, F_{z}$ and $T_{y}$ with a linear actuator in combination with a checkerboard magnet array can be controlled in the same way as in a conventional linear actuator [8] 

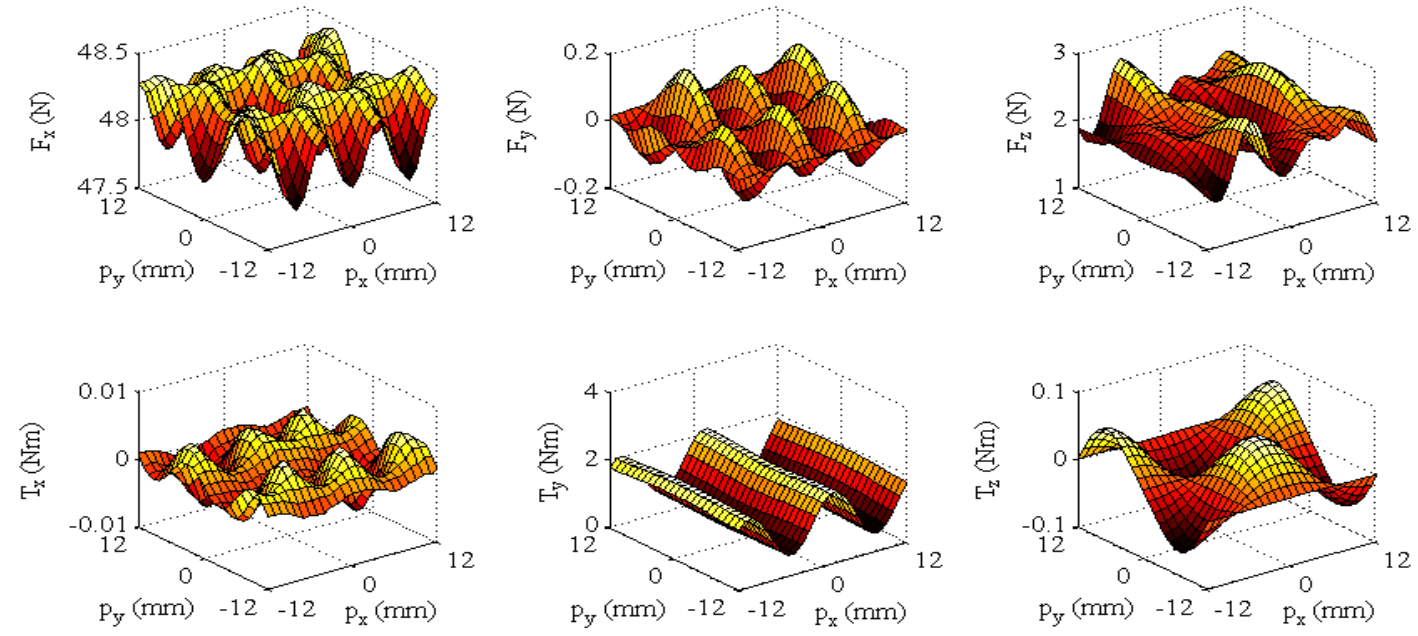

Fig. 6. Electromagnetic force and torque profiles produced by a single linear actuator when the peak current is applied to the q-axis.

\section{DOF control of the ceiling actuator}

To magnetically suspend the translator underneath the ceiling and move it over large distances in the $x y$-plane, its 6 DOF position is controlled using the diagram shown in Fig. 7.

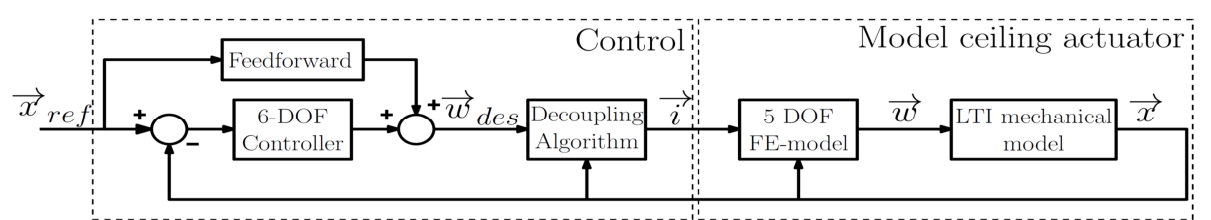

Fig. 7. Diagram for 6 DOF position controller of the translator.

5 DOF FE-model of the ceiling actuator

To estimate the effect of the force and torque ripples on the tracking performance of the controller, a 5 DOF motor model is created based on the 3D FE-results of the single linear actuator. It assumes that the force and torque profiles of the single linear actuator periodically repeat when the actuator is moved over $2 \tau_{p}$ in either the $x$ or $y$ direction. As a result, the profiles for each linear actuator fixed to the translator is obtained by appropriately shifting and transforming the profiles of Fig. 4, 5, and 6. Each translator is shifted away from translator's mass center point as indicated in Fig. 1. Again, the mass center point is located $10(\mathrm{~mm})$ below the iron yokes.

The profiles are only obtained as function of $p_{x}$ and $p_{y}$, while the $p_{z}$ is fixed $\left(p_{z}=h_{g}\right)$. Considering the analytical model, variations of $p_{z}$ are accounted for by scaling the reluctance forces and torques profiles according to

$$
c_{\text {rel }}\left(p_{z}\right)=e^{\frac{2 \pi}{\tau_{p}}\left(h_{g, e f f}\left(h_{g}\right)-h_{g, e f f}\left(p_{z}\right)\right)} .
$$

Similar to the reluctance components, the electromagnetic force and torque profiles are scaled with

$$
c_{e m}\left(p_{z}\right)=e^{\frac{\pi}{\tau_{p}}\left(h_{g, e f f}\left(h_{g}\right)-h_{g, e f f}\left(p_{z}\right)\right)} .
$$

For an airgap deviation of $1 \mathrm{~mm}$, scaling in this manner results in a maximum error of $5 \%$ in the average thrust and normal force when compared to FE-simulations. The rotations $\psi$ and $\theta$ are accounted for by calculating $p_{z}$ for the individual linear actuator at the points indicated in Fig. 1 . The effect of $\phi$ is not considered. Hence the name 5-DOF FE-model.

The electromagnetic force and torque profiles are divided by the respective test currents and then multiplied by the current vector $\vec{i}$ obtained from the decoupling algorithm. Finally, the wrench vector, $\vec{w}=\left[F_{x} F_{y} F_{z} T_{x} T_{y} T_{z}\right]^{T}$, acting on the mass center point is obtained as the sum of the forces and torques produced by each linear actuator. 
Decoupling algorithm

The same decoupling algorithm as presented in Section III is applied to control the forces and torques. For the 6 DOF simulations an approximation model for a single linear actuator is used, however. Because of the small force ripples as shown in Fig. 4, 5, and 6, the thrust and normal force are modeled with (6) and (8). In this case, $k$ and $F_{z, r}$ are obtained from the 3D FE results. Based on the FE-results, only $T_{y}$ is approximated

$$
\begin{aligned}
T_{y}\left(p_{x}\right) & =T_{y, r}\left(p_{x}\right)+k_{T_{y, d}}\left(p_{x}\right) I_{d}+k_{T_{y, q}}\left(p_{x}\right) I_{q} \\
& =k_{1, r} \sin \left(\frac{2 \pi}{\tau_{p}} p_{x}\right)+k_{2, r} \sin \left(\frac{2 \pi}{\tau_{p}} p_{x}\right)+k_{2, d} \sin \left(\frac{2 \pi}{\tau_{p}} p_{x}\right) I_{d}+\left[k_{0, q}+k_{2, q} \sin \left(\frac{2 \pi}{\tau_{p}} p_{x}+\frac{\pi}{2}\right)\right] I_{q}
\end{aligned}
$$

In [8], it has been experimentally shown that using (15) this torque component can be accurately controlled in a conventional linear actuator. The unknown coefficients are obtained from curve fitting (15) on the results obtained from 3D FE simulations. Although it is possible to describe the force and torque ripples more accurately, it will make the model more complex. Using (6), (8), and (15), the force and torque produced by each linear actuator is obtained by shifting and transforming the model in the same way as described for the 5 DOF FE-model. It has to be mentioned that these models do not consider $p_{z}$ or any of the rotations.

Mechanics and controller

Because stiff body dynamics are assumed (all forces and torques are supposed to be acting in the translator's mass center point) and friction is negligible, the linear-time-independent mechanics of the ceiling actuator are modeled as a free moving mass or inertia for each DOF. Due to the low force ripples shown in the FE-results, it is assumed that the decoupling algorithm provides sufficient decoupling of the forces and torques. Consequently, the ceiling actuator can be stabilized using six SISO controllers. For each DOF a lead-lag controller in combination with a high frequency roll-off filter has been designed

$$
C(s)=7.51 \cdot 10^{11} \cdot M \frac{(s+99.35)(s+31.42)}{s(s+993.5)\left(s^{2}+1571 s+2.467 \cdot 10^{6}\right)}
$$

where $\mathrm{M}$ is mass or inertia of the corresponding DOF. For the three translator positions, $M=12 \mathrm{~kg}$. Because of the symmetric structure of the translator $M=53 \mathrm{~g} \cdot \mathrm{m}^{2}$ for the rotations $\psi$ and $\theta$, while $\mathrm{M}=97 \mathrm{~g} \cdot \mathrm{m}^{2}$ for the rotation $\phi$. The controller results in a closed-loop bandwidth of $50 \mathrm{~Hz}$ and high frequency roll-off at $500 \mathrm{~Hz}$. Acceleration feed-forward is added to improve the tracking performance of the feed-back system.

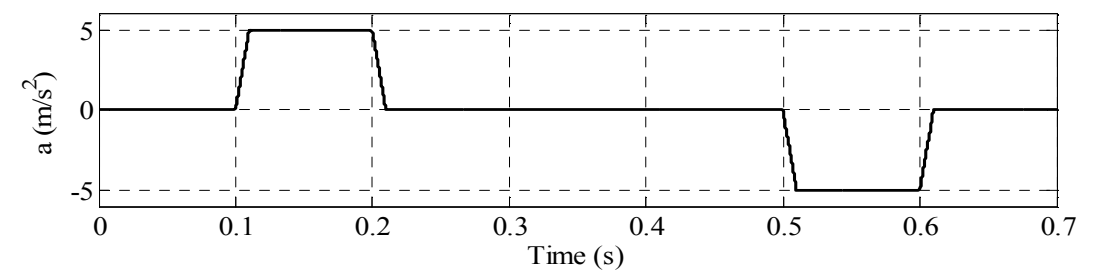

Fig. 8. Reference acceleration profile.
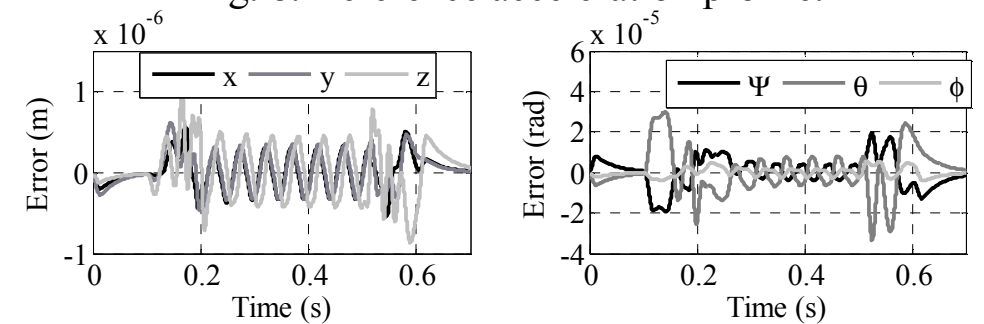

Fig. 9. Simulated position errors (left) and angle errors (right).

\section{DOF simulations}

The 6 DOF controller, decoupling algorithm, and 5 DOF FE-model have been implemented in Matlab Simulink. During simulations, the translator follows the same third order motion along $x$ and $y$. The reference acceleration is shown in Fig. 8 and it corresponds to a stroke of $200 \mathrm{~mm}$, a maximum 
velocity of $0.5 \mathrm{~m} / \mathrm{s}$, and a jerk of $500 \mathrm{~m} / \mathrm{s}^{3}$. Additionally, $p_{z, r e f}=h_{g}=2.75 \mathrm{~mm}$ and the reference angles are set to $0 \mathrm{rad}$. As shown in Fig. 9, the 6 DOF controller is able to track the position within $1 \mu \mathrm{m}$ and limit the angle errors to $30 \mu \mathrm{rad}$. The maximum current density is $9.64 \mathrm{~A} / \mathrm{mm}^{2}$, which is below the limit for saturation. The mean losses are estimated at $91 \mathrm{~W}$.

\section{Conclusions}

The design and control of a magnetically suspended ceiling actuator with infinite planar stroke has been presented. It combines four iron-cored linear actuators and a checkerboard PM array. For the optimization, an analytical model has been derived which accounts for the flux density inside the iron yoke. The resulting optimized design requires a low magnetic loading to reduce the passive attraction force. Therefore, a PM grade with a low remanence has been selected. It has also been shown that a three-phase, iron-cored linear actuator in combination with a checkerboard PM array only produces considerable force and torque components which are comparable to those produced by a conventional linear actuator. Moreover, the forces and torques in the ceiling actuator can be controlled by applying Park's transformation. The force ripples of the optimized design have been obtained from FE-analysis and it has been shown that these ripples result in position errors of $1 \mu \mathrm{m}$ and angle errors of $30 \mu \mathrm{rad}$ when the ceiling actuator is controlled in $6 \mathrm{DOF}$.

\section{References}

[1] T.T. Overboom, J.P.C. Smeets, J.W. Jansen, and E. Lomonova, "Topology comparison for a magnetically suspended ceiling actuator," Proc. of the 2011 IEEE Int. Electrical Machines and Drives (IEMDC), Niagara Falls (Canada), pp.296-301, May 2011.

[2] T.T. Overboom, J.P.C. Smeets, J.W. Jansen, and E. Lomonova, "Design and operating principles of a magnetically suspended ceiling actuator with fail-safe operation," Proc. of the 12th EUSPEN Int. Conf., Stockholm (Sweden), pp.296-301, June 2012.

[3] J.W. Jansen, C.M.M. van Lierop, E.A. Lomonova, and A.J.A. Vandenput, "Magnetically levitated planar actuator with moving magnets," IEEE Trans. on Industry Applications, 44(4), pp.1108-1115, 2008.

[4] I.J.C. Compter, "Electro-dynamic planar motor," Precision Engineering, 28(2), pp.171-180, 2004.

[5] J. Wang, G.W. Jewell, and D. Howe, "A general framework for the analysis and design of tubular linear permanent magnet machines," IEEE Trans. on Magnetics, 35(3), pp. 1986-2000, 1999.

[6] W.J. Kim, D.L. Trumper, and J.H. Lang, "Modeling and vector control of planar magnetic levitator," IEEE Trans. on Industry Applications, 34(6), pp.1254-1262, 1989.

[7] T.T. Overboom, J.P.C. Smeets, J.W. Jansen, and E. Lomonova, "Semianalytical calculation of the torque in a linear permanent-magnet motor with finite yoke length," IEEE Trans. on Magnetics, 48(11), pp. 3575-3578, 2012.

[8] T.T. Overboom, J.P.C. Smeets, J.W. Jansen, and E. Lomonova, "Torque decomposition and control in an iron core linear permanent magnet motor," Proc. of the 2012 IEEE energy conversion congress and exposition (ECCE), Raleigh (North Carolina), pp.2662-2669, Sept. 2012. 